Original Article

\title{
THE RELATIONSHIP BETWEEN DENTAL ARCH DIMENSIONS \& INCISAL ABNORMALITIES TO THE MISARTICULATION OF CONSONANTS IN CHILDREN WITH ORAL CLEFTS
}

\author{
Amarshree Shetty ${ }^{1}$, Kavita Rai ${ }^{2}$, Amitha M. Hegde ${ }^{3}$, T. Dattatreya ${ }^{4}$ \\ ${ }^{1}$ Reader, Ph.D Scholar, ${ }^{2}$ Professor, ${ }^{3}$ Professor \& Head of the Department, Department of Pedodontics \& Preventive \\ Dentistry, A.B.Shetty M emorial Institute of Dental Sciences, Nitte University, Mangalore, Karnataka \\ ${ }^{4}$ Professor \& Principal, Nitte Institute of Speech \& Hearing, M angalore University, M angalore, Karnataka \\ Correspondence: \\ Amarshree Shetty \\ Reader, Ph.D Scholar, Department of Pedodontics \& Preventive Dentistry, \\ A.B. Shetty M emorial Institute of Dental Sciences, Nitte University, M angalore - 574160, Karnataka \\ Mobile : +91 9845353251 Fax: +918242204776 \\ E-mail : dramarshreeshetty@gmail.com
}

\begin{abstract}
:
The objective of the present study was to evaluate the association between the dental arch dimensions and the incisal abnormalities or anomalies, to the consonant mis-articulations in children with unilateral cleft palate with the involvement of lip, before and after surgical correction. 50 Non-syndromic children with unilateral cleft palate belonging to various experimental groups and 25 non-cleft children (control group) between the age group of 7-9 years were selected for the study. Dental arch dimensions were measured on the dental casts $\&$ the selected consonants were evaluated from all the four groups, by 3 qualified speech pathologists and then statistically analyzed. Reduction in the dental arch dimensions was observed in children with untreated cleft palate which further decreased after surgery. The correct production of all the selected consonants/ta/, /da/, /tha/, / dha/, /na/, /na/, /la/, /sa/ and /sha/ which was observed to be $15 \%$ in the untreated CP group, improved upto $52.4 \%$ after surgical correction in spite of the reduction in the dental arch dimensions. Speech analysis showed a high percentage of distorted sounds were maximum in untreated CP patients which decreased in surgically treated CP patients. Substituted sounds which was found to be absent in untreated cleft palate patients was observed in children who had undergone surgical correction of the palate Conclusion: the reduced arch dimensions and incisal abnormalities may be contributing factors which do not allow $100 \%$ normal speech in children with oral clefts.
\end{abstract}

Keywords: Cleft palate, Dental arch dimensions, Consonant production, Speech

\section{Introduction:}

Cleft lip/palate is one of the most common structural birth defect that affects approximately $1 / 800$ live births(Bender 2000). ${ }^{1}$ A child with an oral cleft is born with the unique challenge to fight against various problems relating to appearance, dental arch dimensions, growth of the face and speech development.

Access this article online Quick Response Code
The key to successful management of children with clefts lies in a multidisciplinary team a p proach, with treatments including multiple surgeries, speech therapy, dental and orthodontic treatments over first 18 years of life ${ }^{2}$, that is essential in view of the complex effects that clefts and the related speech defects may have on a child's development, relationships, confidence and self-esteem. It is estimated that India has approximately 36,000 cleft births annually which makes it one of the countries most in need for programs dealing with cleft rehabilitation ${ }^{3}$. Unfortunately in India more importance is given only to the surgical management, while dental rehabilitation and problems regarding their speech is still neglected.

Children born with cleft of the lip and palate are at risk for resonance, articulation and expressive language problems that impair communication for many years ${ }^{4}$.

The atypical articulatory patterns of articulation observed 
in the speech of individuals with cleft palate appear to develop in compensation for velopharyngeal inadequacy, whereas others develop in compensation for palatal fistulae or malocclusion ${ }^{5}$. These individuals often produced nasals and sounds with glottal place of articulation ${ }^{6}$. It has been noted that children with cleft palate have difficulty in producing high pressure consonants, additionally; the reduced hard palate surface area makes it difficult to produce sounds with an alveolar or palatal place of articulation ${ }^{6}$.

Consonants are sounds produced when the air stream in the vocal tract is interrupted completely or partially. They are either voiced or produced without vocal cord vibrations (M osby year book). In cleft palate patients, the failure to build up sufficient amount of oral breath pressure is the main cause for consonant mis-articulation. For the proper pronunciation of the consonants, the dental arch and its associated structures play a major role ${ }^{7}$. The children with oral clefts often present a defective arch associated with abnormalities in the anterior teeth ${ }^{8}$. Hence the present study was done to evaluate the association between abnormalities of the dental arch and the misarticulated consonants in children with unilateral oral clefts with the involvement of lip, before $\&$ after surgical correction.

\section{Materials and Methods :}

50 non-syndromic children with unilateral cleft palate and 25 non-cleft children (control group) between the age group of 7-9 years were selected for the study. Selected children were from the department of Pedodontics and preventive dentistry at A.B Shetty memorial institute of dental sciences and from Nitte Meenakshi Craniomaxillofacial centre who had reported for dental treatment and/ or surgical correction of the clefts.

The patient's records were reviewed for cleft type and extent, associated syndromes and anomalies and speech analysis. Only patients with normal hearing and without any syndrome or psychomotor problems were included in the study group. The selected children had their palatal surgery done at the mean age of 4.5 years and had not undergone any sort of orthodontic or prosthodontic treatment post surgical intervention.

The selected children were categorized into 3 groups:

GROUPI : 25 children who have been certified as medically fit with normal speech, language and hearing. (Control group).

GROUP II : 25 untreated children with unilateral cleft palate with involvement of the lip.

GROUP III : 25 surgically treated children with unilateral cleft palate with involvement of the lip.

\section{Dental Arch M easurements:}

Study models for all the three groups of children were made based on the proper duplication and anatomical landmarks for the assessment of dental arch dimensions. The reference points were marked on the dental casts.

Points of reference: The Central fossa of the first permanent molars on either side as the 1st (Point B), $2^{\text {nd }}$ (Point C) reference point, and the frontal edge of the incisive papilla (Point A) as the 3 rd reference point. (Fig 1)

The maxillary dental arches of all the patients were assessed for Inter-molar arch width (IM), Palatal depth $(P D)$, Palatal length (PL) and the clinical presence of incisal abnormality respectively.

The intermolar arch width (IM), palatal depth (PD) and palatal length $(\mathrm{PL})$ were measured simultaneously with the help of a three dimensional KORKHAUS CALIPERS (Fig1) $)^{9,10}$. The clinical presence of incisal abnormalities which included agenesis and/or rotation of the tooth were also observed.

\section{Consonant selection:}

The speech of the selected samples which consisted of 25 non-cleft subjects and 50 cleft subjects was tape recorded in a sound treated room by three experienced speech pathologists. Audiological evaluation of all the subjects was done by the audiologist to rule out any hearing problems. The speech analysis was carried out with the help of standard materials which were used in conjunction 
with syllable repetition, picture description, counting from 1-20 and general conversation ${ }^{1}$.Standard materials used are specific tests to a particular language which analyzes all the sounds in that language at the initial, medial and final positions of the word. The languages used here were Kannada, Malayalam and English.

The anatomical variable considered/selected in the present study was palatal arch dimension and the incisors of the maxillary arch. The consonants/ta/, / da/, / na/ , / /a/, /sha/ which required palatal placement of articulation for their correct pronunciation was selected for the study. As there was also the variable of dentition, the sounds /tha/, /dha/,/na/ \&/sa/ were selected.

The production of the consonants/ta/, / da/, /tha/, / dha/, /na/, / na/, /la/, / sa/ and / sha/ were checked for errors of distortion, omission and substitution. To ensure that the interpretations by the 3 audiologists were identical, interjudge agreement was assessed by having each patient's consonant production values checked at the same time by all the 3 speech pathologists. The categorizing of distortions, substitutions and omissions was based on $100 \%$ consensus between them.

The data gathered was subjected to statistical analysis. Chisquare test was applied for consonant analysis as the data represents a qualitative nature. The data gathered for the palatal arch dimensions and incisal abnormalities is quantitative in nature facilitating the application of ANNOVA. Turkeys test was done for inter comparison between groups.

\section{Results :}

\section{Dental Arch Dimensions:}

All the three parameters, the intermolar arch width (IM), palatal height $(\mathrm{PH})$ and the palatal length $(\mathrm{PL})$ were measured in all the 3 groups of selected patients from their study models and the mean values were recorded. The comparison of the three parameters showed that, the mean values obtained with the untreated cleft palate study group was slightly less than the control group, and was statistically significant. Whereas, the treated cleft palate group showed reduction in all the dimensions which was statistically very highly significant. [Table 1]

\section{Incisal Abnormalities:}

The prevalence of missing lateral incisors were found to be highest which was seen in $56 \%$, followed by rotated central incisors with missing lateral incisors which were seen in $20 \%$, followed by rotated lateral incisors which was seen in $14 \%$ and finally rotated central incisors with rotated lateral incisors which were seen in $16 \%$ of the cleft group respectively.

\section{Consonant Analysis:}

When the selected consonants were evaluated individually, the production of those consonants/ta/, / da/, /tha/, /dha/, /na/, /na/, /la/, /sa/ \& /sha/ was mostly incorrect in the untreated cleft palate group. The consonants / ta/, / tha/, / dha/ and /la/ which showed total incorrect production before surgery showed definite improvement after surgery ranging from $16 \%(/ \mathrm{sa} /)$ to as high as $80 \%(/$ tha/). Whereas, the production of the consonant / na/ was only at a range of $28 \%$ in a cleft child and did not show any improvement after surgical correction. [Graphl]

On further analysis of incorrect sounds that were detected, it was observed that the percentage of distorted sounds was higher in untreated CP patients, which decreased in surgically treated CP patients. Substituted sounds were found to be absent in untreated cleft palate patients, but they were observed in children who had undergone surgical correction of the palate. [Graph I].

The correct production of all the selected consonants/ta/, / da/, / tha/, / dha/, / na/, / na/, /la/, /sa/ and/sha/ which was observed to be just $15.11 \%$ in the untreated CP group, improved upto $53.3 \%$, showing an overall improvement of $38.2 \%$ after surgical correction in spite of the reduction in the dental arch dimensions. However, the production of consonants in relation to the dental arch dimensions was not statistically significant.

As the anterior incisors were one of the variables considered in the selection of the consonants, the 
dentoalveolar consonants/tha/, / dha/, / na/ and/sa/ were selected. The production of consonants/tha/,/dha/ \&/na/ showed improvement after surgical correction, whereas, the production of consonant/sa/ was observed to be weak in spite of surgical correction. But in any of the dentoalveolar consonants no significant relationship could be established between the error in the consonants and the incisal abnormalities observed.

\section{Discussion :}

Ranta $\mathrm{R}^{12} \& \mathrm{Marco} \mathrm{Vich}^{13}$ have stated that, permanent lateral incisor is the tooth missing most frequently in the cleft area, which is in accordance with our present study, where the prevalence of missing lateral incisor was found to be the highest (56\%). Robert J Shprintzen and Janusz Bardach observed that the permanent central incisors adjacent to a cleft area are found to erupt in a rotated position. Similar observations were made in the present study where the prevalence of rotated central, rotated lateral incisor and missing lateral incisor were high.

The impact of clefting on the speech of children with cleft palate has been described by several investigators. It has been stated that, prior to the surgical repair of the palate, children with cleft palate have difficulty in producing pressure consonants ${ }^{14-18}$. According to the observations of 0 'Gara et $\mathrm{al}^{16}$, the children with Cleft palate primarily seem to avoid sounds normally produced at the palate.

On the evaluation of the selected consonants in the present study, misarticulations in relation to all the consonants were observed in untreated cleft group which was as high as $85 \%$. The consonants/ta/ , / da/, / tha/ , / dha/, /sa/ \& /sha/ which were pressure consonants and their misarticulations observed in the untreated CP group may be attributed to their inability to build up intra oral breath pressure required for the correct production of the consonants, due to the presence of the cleft or due to the defective placement and/ or posturing of the tongue for the sounds of interest.

The treated cleft palate patients in the present study showed significant improvement in the articulation of most of the selected consonants, though a small population of the surgically treated group still exhibited misarticulation. Courtney EJones et al ${ }^{19}$ have stated that children with cleft palate post surgery made gains in the production of consonants. Whereas, Michi $\mathrm{K}$ et $\mathrm{al}^{20}$ had observed a patient with repaired unilateral cleft lip and palate, with articulation disorders involving contact of the tongue to the hard palate following surgical treatment.

It has been stated that, abnormalities in the hard palate, including an unrepaired cleft or maxillary collapse after repair, affect the tongue placement and the posturing as well as airflow through the oral cavity. Jaana Laitenen et al ${ }^{21}$ had also stated that narrow and shorter maxillary arches and as well as shallower palates were related to the problems of misaticulations of $/ r /, / s / \& / / /$ consonants.

Occurrence of articulatory speech disorders has been connected with the absent incisors from the normal developmental processes or occlusal anomalies of the incisors. ${ }^{22,23}$ It has also been stated that, accurate tongue placement is often difficult when there are missing incisor teeth or increased interdental spacing because the tongue frequently slides forward into the gaps during speech causing distortion of both lingual-alveolar and lingualpalatal sounds ${ }^{7}$. The presence of missing lateral and the rotated central incisors that were observed in the present study may be attributed to the misarticulations of the consonants /sa/, /tha/, /dha/ \& / na/ but no significant relationship could be established between the error in these consonants and the incisor abnormalities observed.

Studies of sound acquisition in a normal developing child have shown that correctly produced sounds are acquired over time ${ }^{24,25}$. The expectation is that the same principles apply for the acquisition of sounds following palatal repair and considerable speech therapy. It is also felt that the habit strength of the inadequate articulating movements of a cleft palate child might have influenced the rate of improvement after surgical treatment and considerable speech therapy.

Highly adaptable speech mechanism and widely ranging 
compensatory behaviors can result in adequate articulation even in the presence of severe abnormalities of the orofacial structures. Therefore the size of the dental arches should be considered only a possible contributing hazard to clear sound production ${ }^{25}$. However, in the present study it has been found that, the variability of the palatal arch dimension and the incisor abnormalities may be contributing factors in the errors of consonant production.

\section{Conclusion :}

The misarticulation/incorrect production of the selected consonants were observed to be high in the untreated cleft palate group.

Surgically treated cleft palate group without speech therapy showed significant improvement in the pronunciation of the consonants in comparison to the untreated cleft palate group inspite of reduction in the dental arch dimensions.

The comparison of the dental arch dimensions and the incisal abnormalities to the production of consonants showed no significant statistical relationship.

\section{Acknowledgement :}

I would like to thank Prof T. Dattatreya, Principal, Nitte Institute of Speech \& Hearing, Mangalore University and the Nitte Meenakshi Craniofacial Centre for Clefts for all the support extended throughout the study.

\section{FIGURE 1-DENTAL ARCH M EASUREM ENTS}

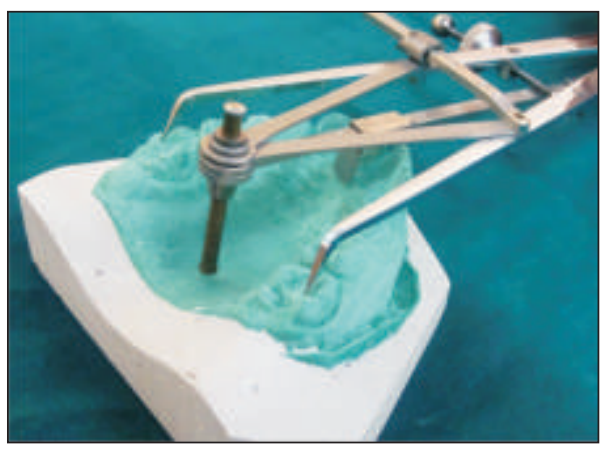

Footnote: A - Palatal Depth, B - Intermolar Width

The intermolar arch width (IM), palatal depth (PD) and palatal length (PL) were measured simultaneously with the help of a three dimensional KORKHAUSCALIPERS.
Graph 1: CONSONANT ANALYSIS

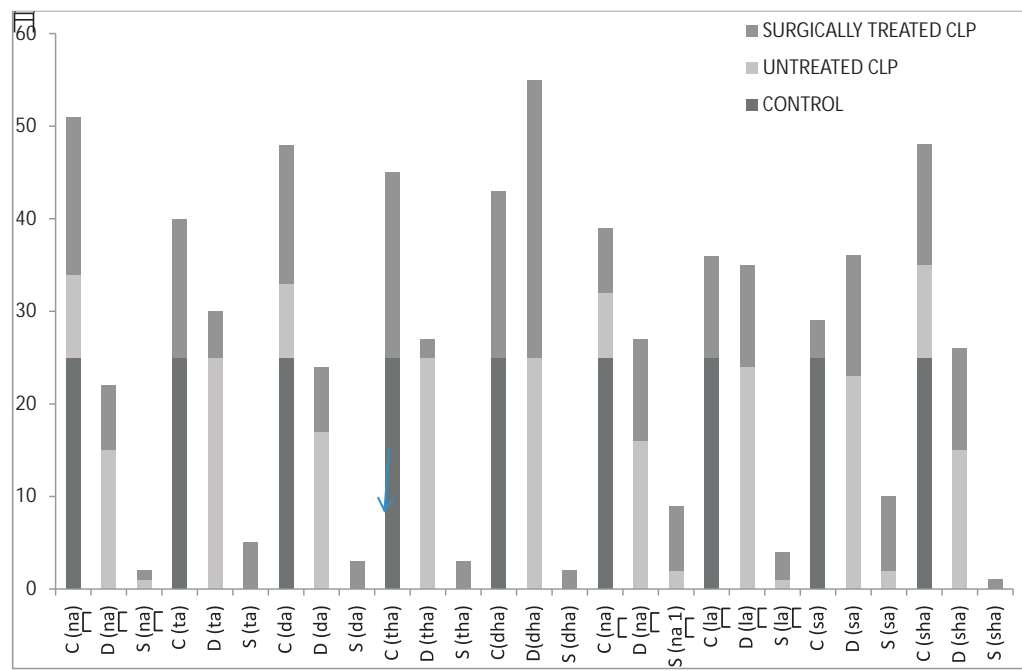

FOOTNOTE:-C:CORRECT,D:DISTORTED,S:SUBSTITUTED

XAXIS:SOUNDS

Y AXIS:NUM BER OF PATIENTS

TABLE 1: DENTAL ARCH DIM ENSIONS

\begin{tabular}{|l|l|l|l|l|}
\hline & $\begin{array}{l}\text { GROUP I } \\
\text { M ean STD }\end{array}$ & $\begin{array}{l}\text { GROUP II } \\
\text { M ean STD }\end{array}$ & $\begin{array}{l}\text { GROUP III } \\
\text { M ean STD }\end{array}$ & SIGNIFICANCE \\
\hline $\begin{array}{l}\text { Intermolar } \\
\text { arch width } \\
\text { (IM) }\end{array}$ & $32.44+2.103$ & $32.16+2.54$ & $30.36+2.41$ & $\begin{array}{l}0.005 \\
\text { Highly significant }\end{array}$ \\
\hline $\begin{array}{l}\text { Palatal depth } \\
\text { (PD) }\end{array}$ & $14.96+1.46$ & $14.12+1.64$ & $11.4+1.96$ & $\begin{array}{l}<0.001 \\
\text { Very Highly significant }\end{array}$ \\
\hline $\begin{array}{l}\text { Palatal length } \\
\text { (PL) }\end{array}$ & $26.12+2.91$ & $25.32+1.89$ & $23.52+3.28$ & $\begin{array}{l}0.004 \\
\text { Highly significant }\end{array}$ \\
\hline
\end{tabular}


References

1. Bender PL. Genetics of cleft lip and palate. J Pediatr Nurs. 2000; 15(4): 242-9.

2. Van Riper $\mathrm{C}$ and Erickson RL.: Speech Correction. An Introduction to Speech Pathology and Audio logy. Ninth edition. Allyn and Bacon. Boston, London.

3. The Smile Train website: http://www.smiletrain.org/ about_us/qa.htm. Accessed on 22/04/2010.

4. Ingram TTS. A Description and Classification of the Common Disorders of Speech in Children. Arch Dis Child. 1959; 34: 444-455.

5. Peterson-Falzone S], Hardin- Jones MA, Karnell MP. Cleft Palate Speech.2001;Ed 3:pp.165.M osbylnc.

6. Jones CE, Chapman KL, Hardin- Jones MA. Speech development of children with Cleft palate before and after Palatal Surgery. Cleft Palate - Craniofacial Journal 2003; 40(1):19-31.

7. Oljimi H, Maeda K, Torikai K, Sezaki K and Hirakawa T; Longitudinal study of M axillofacial growth after Palatoplasty using the Buccal flap and the Pushback method in UCLP patients: From Infancy to 10 years of age. M ed Bull Fukuoka Univ.2002; 29(2):71-8

8. Kilpelainen PVJ, M aija T. Laine-Alava, Lammi S; Palatal M orphology and Type of Clefting, Cleft Palate craniofacial J. 1996; 33(6): 477-482

9. Weiss $C E$, Gordon ME, Lillywhite HS. Clinical management of Articulatory and Phonologic Disorders. Second edition. 1987. Williams $\&$ Wilkins Publishers. Baltimore, London.

10.F. C. N. De Frietas, E.P.Bastos, L.S.G. Primo \& V.L.N.DeFrietas. Evaluation of the palate dimensions of patients with perennial allergic rhinitis. International J. of Pediatric Dentistry. 2001; 11: 365-37

11. Rakosi T, Jonas I, Graber T .Orthodontic Diagnosis. Theime Medical Publishers Inc., New York. 1993.

12. Ranta R. A review of tooth formation in children with cleft lip/palate. Am .J. Orthod Dentofacial Orthop. July 1986; 90(1): 11-8

13. Vichi M, Franchi L. Abnormalities of the maxillary incisors in children with cleft lip and palate. J of Dentistry for Children. 1995:412-417
14. Grunwell P, Russell J. Vocalisations before and after cleft palate surgery: a pilot study. BrJ Disord Commun.1987; 22: 1-17

15. Grunwell P, Russell J. phonological development in children with cleft lip and palate. Clin Linguist Phonet. 1988; 2: 75-95.

16. O'Gara MM, Logeman JA. Phonetic Analysis of the speech development of babies with cleft palate. Cleft palate J.1988; 25(2):122-34

17. Chapman KL. Vocalisations of toddlers with cleft lip and palate. Cleft Palate Craniofac J.1991; 28: 172-178.

18. Powers G, Dunn C, Erickson C. Speech analysis of four children with repaired cleft palates. J Speech Hear Disord. 1990; 55: 542-550.

19. Courtney E. Jones, Kathy L. Chapman, Mary A Hardin Jones. Speech development of children with cleft palate before and after palatal surgery. Cleft palate craniofacial surgery.2003; 40(1): 19-31.

20. M ichi K, Suzuki N, Yamashita Y, Imai S. Visual training and correction of articulation disorders by use of dynamic palatography: serial observation in a case of cleft palate. J Speech Hear Disord. 1986; 51(3): 222-38

21. Laitenen J, Pulkkinen RRJ and Haapanen M L. The association between dental arch dimensions and occurrence of finish dental consonant misarticulations in cleft lip/palate children. Acta Odontol Scand. 1998; 56: 308-312.

22. Snowk. Articulation proficiency in relation to certain dental abnormalities.J Speech Hear Disord. 1961; 26: 209-212.

23. Weinberg B, A cephalometric study of normal and defective articulation and variations in incisor dentition. J Speech Hear Res. 1968; 11: 288-300

24. Tyler AA, Edwards ML. Lexical acquisition and acquisition of initial voiceless stops. I Child Lang. 1993; 20: 253-73

25. Gierut JA, Morrisette ML, Champion AH. Lexical constraints in phonological acquisition.J Child Lang.: 1999; 26: 261-294. 